88

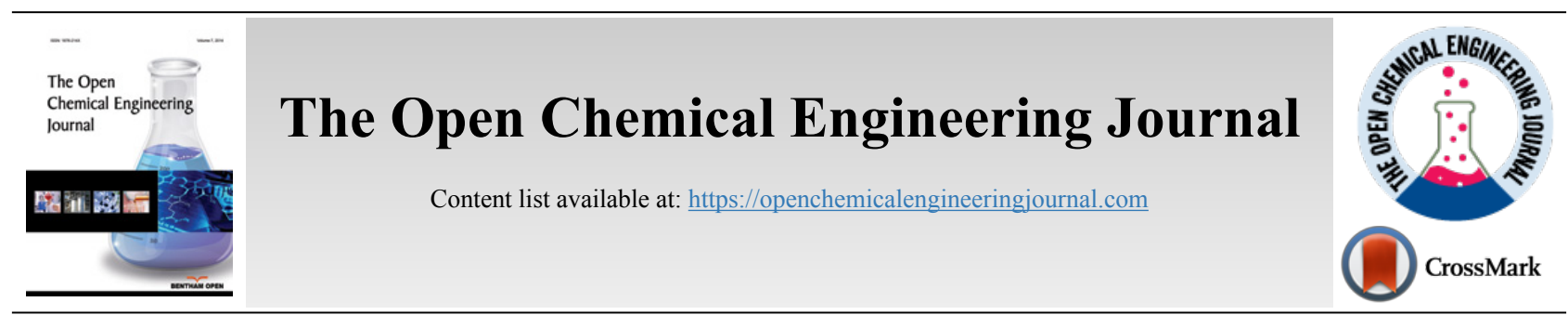

RESEARCH ARTICLE

\title{
Production of Citric Acid from the Fermentation of Pineapple Waste by Aspergillus niger
}

Augustine. O. Ayeni ${ }^{1, *}$, Michael O. Daramola ${ }^{3}$, Olugbenga Taiwo ${ }^{2}$, Omowonuola I. Olanrewaju $^{1}$, Daniel T. Oyekunle ${ }^{1}$, Patrick T. Sekoai ${ }^{4}$ and Francis B. Elehinafe ${ }^{1}$

${ }^{l}$ Chemical Engineering Department, College of Engineering, Covenant University, Ota, Nigeria

${ }^{2}$ Biological Sciences Department, College of Science and technology, Covenant University, Ota, Nigeria

${ }^{3}$ School of Chemical and Metallurgical Engineering, Faculty of Engineering and the Built Environment, University of the Witwatersrand, Wits 2050, Johannesburg, South Africa

${ }^{4}$ Hydrogen Infrastructure Centre of Competence, Faculty of Engineering, North-West University, Potchefstroom, South Africa

\section{Abstract:}

Background:

Citric acid, aside its uses as a cleaning agent, has varied applications in the chemical, pharmaceutical, and food industries. A biotechnological fermentation process is one of the easiest ways to satisfy the demands for this useful commodity.

\section{Methods:}

The fermentation of pineapple waste by Aspergillus niger for the production of citric acid was investigated in this study. STATISTICA 8 release 7 (Statsoft, Inc. USA) statistical software was used for the design of experiments, evaluation, and optimization of the process using the central composite design (CCD), a response surface methodology approach. Lower-upper limits of the design for the operating parameters were temperature $\left(25-35^{\circ} \mathrm{C}\right)$, fermentation time (35-96 h), $\mathrm{pH}(3-6)$, methanol concentration (1-7\%) and glucose (15-85 g/L). Twenty-seven duplicated experimental runs were generated for the $\mathrm{CCD}$ route.

\section{Results \& Conclusion:}

The optimal operating conditions were validated at $38 \mathrm{~g} / \mathrm{L}$ of glucose concentration, $3 \%$ (v/v) of methanol, $50 \mathrm{~h}$ of fermentation time, $\mathrm{pH}$ of 4.3 and temperature of $30{ }^{\circ} \mathrm{C}$ which yielded $15.51 \mathrm{~g} / \mathrm{L}$ citric acid. The statistical significance of the model was evaluated using a one-way analysis of variance. The validated predicted response values obtained from the statistical model showed close relationships with the experimental data.

Keywords: Citric acid, Central composite design, Pineapple waste, Fermentation, Statistical optimization, Aspergillus niger.

\section{Article History}

Received: March 04, 2019

Revised: May 03, 2019

Accepted: May 07, 2019

\section{INTRODUCTION}

Citric acid with the formula $\mathrm{C}_{6} \mathrm{H}_{8} \mathrm{O}_{7}$ is a weak organic acid. It consists of 3 carboxyl (R-COOH) groups [1]. A lot of organic effluents in the form of pomace, seeds, and peels are produced as wastes from the fruit juice industry [2]. Due to the wide use of citric acid, different types of fungi have been used in its production since 1917 and yeasts have also been used since 1960 [3]. Most importantly, citric acid has been produced industrially in more recent years by fungal fermentation of glucose or sucrose mainly by Aspergillus niger, using various

Address correspondence to this author at the Chemical Engineering Department, College of Engineering, Covenant University, Ota, Nigeria;

Tel: +2348055745627; Emails: augustine.ayeni@covenantuniversity.edu.ng; aoayeni@gmail.com raw materials as substrates. Some raw materials that are readily available and inexpensive previously used as substrates include: corn-cobs, rapeseed oil, carob pod extract, kiwi-fruit peel, mandarin orange, grape and apple pomace, and brewery wastes. A. niger has however remained the most preferred organism due to a number of factors: the capacity of utilizing cheaper raw materials, genetic stability, high yield of product and absence of undesirable reactions $[4,5]$.

With a world production of above 18 million tonnes as at 2009 , pineapple ranks $12^{\text {th }}$ amongst fruit crops around the world [6]. Nigeria ranked $6^{\text {th }}$ on the list for world pineapple production with nearly 800,000 tonnes produced annually [7, 8]. However, pineapple waste is commonly dumped on landfills resulting in environmental pollution [9]. Utilization of 
fruits and vegetable effluent provides an economically feasible method of producing citric acid [10]. Furthermore, since pineapple is a perennial plant, there is a steady supply of raw materials, which in turn reduces the costs of citric acid production [10]. Pineapple waste which is agro-industrial based waste also has roles to play in evolving bio-commodities production $[11,12]$. With the need to meet increasing citric acid demands, and overcoming the present challenges of pollution, industrialists need to optimize, especially the process variables (conditions) of the citric acid production, due to their impact on the process economy [3]. The global demand for citric acid is increasing at an unprecedented rate due to its diverse application (preservative, antioxidant, $\mathrm{pH}$-regulator, acidulant, etc.) $[2,13$ - 16]. Therefore, there is a need to develop strategies that will optimize its process yields. Several physicochemical parameters and nutritional requirements which favour the biotechnological production of citric acid have previously been reported in the literature [17 - 19]. These nutritional requirements include the inoculum size, substrate concentration, temperature, $\mathrm{pH}$, etc. [17 - 19]. Looking critically at how the operating parameters interact and affect the citric acid production process is very crucial. These process variables during the fermentative citric acid production are not well understood in the literature. Mathematical and statisticalbased methods such as Response Surface Methodology (RSM) could help in understanding the main and the interactive effects during citric acid production, thereby enhancing the production process yields. RSM has been used in understanding the parametric effects on various bioprocesses such as the production of yoghurt [20 - 22].

There are several published studies using different synthetic routes and different starting materials for the production of citric acid [23]. It was reported that chemical methods are not as economical compared to the fermentation process. In the chemical processing route, the starting materials are worth more than the final product $[23,24]$. Industrial production of citric acid by fermentation using cheap raw materials like pineapple waste will be helpful in economic development.

Design of experiment (DOE) methodology which is a robust technique for process optimization [2] was accurately used in this study. The effect of the various operating variables (glucose concentration, effects $\mathrm{pH}$, temperature, methanol concentration, fermentation time) on citric acid production were adequately evaluated. This study optimizes the result via the CCD approach with the development of a regression model to explain the influence of the variables on the yield of citric acid. The low-high levels of the operating parameters of temperature, time, $\mathrm{pH}$, methanol concentration, and glucose concentration for the experimental design were chosen based on the optimum validated conditions obtained in our earlier studies where apple pomace and corn steep liquor were used as the feed-stocks [2]. The study also demonstrated the feasibility of pineapple waste (a cheap raw material) as a potential substrate for the manufacture of citric acid.

Table 1. Design matrix and citric acid yield obtained after the fermentation process.

\begin{tabular}{|c|c|c|c|c|c|c|c|c|}
\hline- & Temperature & Time & pH & Methanol & Glucose & Observed citric & Predicted citric & Residuals \\
\hline Run order & ${ }^{\circ} \mathrm{C}$ & $\mathbf{h}$ & & conc $(g / L)$ & $\operatorname{conc}(\mathrm{g} / \mathrm{L})$ & acid yield $(g / L)$ & acid yield $(\mathrm{g} / \mathrm{L})$ & $(\mathrm{g} / \mathrm{L})$ \\
\hline 1 & 25 & 10 & 5 & 24 & 3 & 12.33 & 12.30 & 0.03 \\
\hline 2 & 30 & 40 & 6 & 60 & 4 & 11.77 & 11.73 & 0.04 \\
\hline 3 & 30 & 40 & 3 & 60 & 7 & 12.20 & 11.77 & 0.43 \\
\hline 4 & 30 & 110 & 3 & 60 & 4 & 10.36 & 10.19 & 0.17 \\
\hline 5 & 30 & 30 & 3 & 60 & 4 & 10.28 & 10.21 & 0.07 \\
\hline 6 & 40 & 40 & 3 & 60 & 4 & 13.18 & 11.91 & 1.27 \\
\hline 7 & 25 & 80 & 2 & 96 & 6 & 12.97 & 12.71 & 0.26 \\
\hline 8 & 25 & 10 & 2 & 96 & 3 & 13.28 & 13.50 & -0.22 \\
\hline 9 & 25 & 10 & 2 & 24 & 6 & 10.31 & 10.40 & -0.10 \\
\hline 10 & 35 & 80 & 5 & 96 & 6 & 10.23 & 9.73 & 0.50 \\
\hline 11 & 25 & 80 & 5 & 24 & 6 & 12.38 & 12.31 & 0.07 \\
\hline 12 & 30 & 40 & 0 & 60 & 4 & 12.10 & 12.12 & -0.02 \\
\hline 13 & 35 & 80 & 2 & 24 & 6 & 11.20 & 11.35 & -0.15 \\
\hline 14 & 25 & 80 & 2 & 24 & 3 & 14.29 & 14.05 & 0.25 \\
\hline 15 & 30 & 40 & 3 & 60 & 1 & 12.66 & 12.42 & 0.24 \\
\hline 16 & 35 & 10 & 2 & 24 & 3 & 11.69 & 11.77 & -0.08 \\
\hline 17 & 30 & 40 & 3 & 72 & 4 & 15.51 & 15.54 & -0.03 \\
\hline 18 & 35 & 80 & 2 & 96 & 3 & 12.74 & 12.87 & -0.13 \\
\hline 19 & 25 & 10 & 5 & 96 & 6 & 10.08 & 11.74 & -1.67 \\
\hline 20 & 20 & 40 & 3 & 60 & 4 & 10.26 & 10.55 & -0.29 \\
\hline 21 & 35 & 10 & 5 & 96 & 3 & 10.36 & 10.12 & 0.24 \\
\hline 22 & 30 & 40 & 3 & 12 & 4 & 11.13 & 10.87 & 0.26 \\
\hline 23 & 35 & 10 & 2 & 96 & 6 & 10.92 & 11.11 & -0.18 \\
\hline 24 & 30 & 40 & 3 & 60 & 4 & 10.46 & 11.08 & -0.62 \\
\hline
\end{tabular}


(Table 1) contd.....

\begin{tabular}{|c|c|c|c|c|c|c|c|c|}
\hline- & Temperature & Time & pH & Methanol & Glucose & Observed citric & Predicted citric & Residuals \\
\hline Run order & ${ }^{\circ} \mathrm{C}$ & h & & $\operatorname{conc}(g / L)$ & $\operatorname{conc}(g / L)$ & acid yield (g/L) & acid yield (g/L) & $(g / L)$ \\
\hline 25 & 25 & 80 & 5 & 96 & 3 & 10.33 & 10.44 & -0.11 \\
\hline 26 & 35 & 10 & 5 & 24 & 6 & 13.02 & 13.06 & -0.04 \\
\hline 27 & 35 & 80 & 5 & 24 & 3 & 10.49 & 10.67 & -0.18 \\
\hline
\end{tabular}

\section{MATERIALS AND METHODS}

\subsection{Raw Materials}

The wild type of Aspergillus niger was obtained from the Biology Laboratory, Department of Biological Sciences, Covenant University, Ota Nigeria. Pineapples wastes were collected from the Cafeteria of Covenant University, Ota, Nigeria.

\subsection{Procedure and Pretreatment}

Pineapple peels were air dried for about 8 hours and further dried in a convention oven for $2 \mathrm{~h}$ at $60^{\circ} \mathrm{C}$ and then screened to fractional sizes. Screened particle sizes of $2 \mathrm{~mm}$ were used for this study. The spore suspension used for the A. niger was $0.5 \%$ of the standard McFarland solution (a chemical solution of $1 \% \mathrm{BaCl}_{2}(0.05 \mathrm{~mL})$ and $1 \% \mathrm{H}_{2} \mathrm{SO}_{4}(9.95 \mathrm{~mL})$ to a bacterial suspension of $1.5 \times 10^{8} / \mathrm{mL}$. The turbidity of the McFarland solution was compared to the bacterial suspension. Process variables studied were glucose concentration, $\mathrm{pH}$, temperature, methanol concentration and fermentation time. Based on these selected variables, CCD of the STATISTICA software generated 27 different experimental runs (Table 1). The $\mathrm{pH}$ was adjusted using $0.1 \mathrm{~N} \mathrm{HCl}$ or $0.1 \mathrm{~N} \mathrm{NaOH}$ as the case may be.

\subsection{Fermentation Process}

The fermentation process involved the initial preparation of media, inoculation, and incubation for the specified period as stated in the experimental design. The amount of citric acid produced was determined titrimetrically.

The inoculation of the fermentation media was prepared by mixing $1.5 \mathrm{~g}$ substrate in $250 \mathrm{ml}$ Erlenmeyer flasks with the volume raised to $50 \mathrm{~mL}$ with distilled water. The whole mass was autoclaved for $15 \mathrm{~min}$ at $121{ }^{\circ} \mathrm{C}$ prior to the fermentation process. Thereafter, it was cooled to room temperature. A. niger was used to inoculate each medium with the addition of methanol $(0-5 \%)$ to the flasks. During the fermentation, the operational set point parameters were kept as specified in the design. The fermentation process of the inoculum media was conducted in duplicate in an orbital incubator at 180 revolutions per minute at specified operational temperature.

\subsection{Citric Acid Determination}

In order to determine the citric acid produced after fermentation, $0.1 \mathrm{M} \mathrm{NaOH}$ was titrated against the extract (juice) using phenolphthalein as an indicator [25]. The equivalent number of moles of $\mathrm{NaOH}$ required to neutralize citric acid, $\mathrm{C}_{3} \mathrm{H}_{5} \mathrm{O}(\mathrm{COOH})_{3}$, the content of the pineapple juice was determined based on the concentration and volume of $\mathrm{NaOH}$ solution used during titration (Eq. (1)).
Moles $\mathrm{NaOH}$ required $=$ vol of $\mathrm{NaOH}$ required $(\mathrm{mL}) \mathrm{x}$ concentration of $\mathrm{NaOH}(\mathrm{moles} / \mathrm{L}) \times 10^{-3}$

The amount in moles of citric acid, $\mathrm{C}_{3} \mathrm{H}_{5} \mathrm{O}(\mathrm{COOH})_{3}$, in the titrated sample was determined according to Equation(2):

Moles $\mathrm{C}_{3} \mathrm{H}_{5} \mathrm{O}(\mathrm{COOH})_{3}=\frac{\text { moles } \mathrm{NaOH} \times 1 \mathrm{~mol} \mathrm{C}_{3} \mathrm{H}_{5} \mathrm{O}(\mathrm{COOH})_{3}}{3 \text { moles NaOH}}$

The concentration (molarity) of citric acid produced was calculated by Eq. (3)

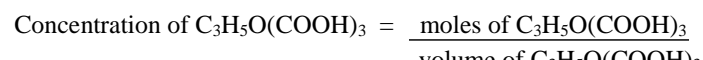

The concentration of $\mathrm{C}_{3} \mathrm{H}_{5} \mathrm{O}(\mathrm{COOH})_{3}$ in $\mathrm{g} / \mathrm{L}$ was determined by Eq. (4) and (5)

Molar mass $=$ Concentration in $\mathrm{g} / \mathrm{L}$ Concentration in $\mathrm{mol} / \mathrm{L}$

Concentration in $\mathrm{g} / \mathrm{L}=$ Concentration in $\mathrm{mol} / \mathrm{L} \times$ Molar mass $(\mathrm{g} / \mathrm{mol})$

\subsection{Model Development}

The experimental data as presented (Table 1 ) were used to generate a second-degree polynomial model (Eq. (6)) that relates citric acid response to the five operational parameters considered in this study.

$$
\begin{aligned}
& \mathrm{Y}=\alpha_{0}+\alpha_{1} \mathrm{~A}+\alpha_{2} \mathrm{~B}+\alpha_{3} \mathrm{C}+\alpha_{4} \mathrm{D}+\alpha_{5} \mathrm{E}+\alpha_{11} \mathrm{~A}^{2}+\alpha_{22} \mathrm{~B}^{2}+ \\
& \alpha_{33} \mathrm{C}^{2}+\alpha_{44} \mathrm{D}^{2}+\alpha_{55} \mathrm{E}^{2}+\alpha_{12} \mathrm{AB}+\alpha_{13} \mathrm{AC}+\alpha_{14} \mathrm{AD}+ \\
& \alpha_{15} \mathrm{AE}+\alpha_{23} \mathrm{BC}+\alpha_{24} \mathrm{BD}+\alpha_{25} \mathrm{BE}+\alpha_{34} \mathrm{CD}+ \\
& \alpha_{35} \mathrm{CE}+\alpha_{45} \mathrm{DE}
\end{aligned}
$$

Where $\mathrm{Y}$ is the yield of citric acid generated, $\alpha_{\mathrm{o}}$ to $\alpha_{45}$ are the model coefficients, A, B, C, D and E are linear coefficients, $\mathrm{A}^{2}, \mathrm{~B}^{2}, \mathrm{C}^{2}, \mathrm{D}^{2}$, and $\mathrm{E}^{2}$ are quadratic coefficients while $\mathrm{AB}, \mathrm{AC}$, $\mathrm{AD}, \mathrm{AE}, \mathrm{BC}, \mathrm{BE}, \mathrm{CD}, \mathrm{CE}$ and $\mathrm{DE}$ represent the interactions between individual parameters on citric acid production. The model coefficients were obtained using the least square estimation method and the most suitable model was selected based on the mean square error (MSE) value. The accuracy of the model fitness was evaluated by the analysis of variance (ANOVA).

\section{RESULTS AND DISCUSSION}

\subsection{Interaction of Parameters on Citric Acid Response}

The results of the experiments are presented in Table $\mathbf{1}$. The highest yield of citric acid $(15.51 \mathrm{~g} / \mathrm{L})$ was observed in experimental run 17 at the prevailing conditions of $30^{\circ} \mathrm{C}, 40 \mathrm{~h}$, $\mathrm{pH}$ of 5 , methanol concentration of $72 \mathrm{~g} / \mathrm{L}$ and glucose concentration of $4 \mathrm{~g} / \mathrm{L}$. Looking closely, the citric acid yield was much lower compared to our previous study [2]. In the 
study [2], better yields of citric acid (with the maximum value of $59.00 \mathrm{~g} / \mathrm{L}$ ) were obtained when the carbon sources were apple pomace and corn steep liquor and at very reduced methanol concentration, reduced $\mathrm{pH}$ of 4.5 , and temperature of $38^{\circ} \mathrm{C}$. These highlight the sensitivity of the operating variables in the citric acid fermentation process which conform to previous studies [26, 27]. Sugar or carbon sources utilization and citric acid yields appear to be a closely related. The more the carbon source is utilized, the more the citric acid yield.

\subsection{Model Development for Citric Acid Production Optimization}

The regression model which explains the influence of the operating variables on citric acid produced is presented in Equation 7. The model statistical significance was evaluated using the analysis of variance (ANOVA). ANOVA together with tools like $\mathrm{R}^{2}$, the sum of squares values, and the $P$ (probability) values validate the model results. $\mathrm{R}^{2}$ value close to unity means that the reliability of the model is very high. A very high $F$-value and low $P$ (probability) value indicate the validity of operating parameters on the dependent variable (citric acid yield). The statistical validation further shows how individual, quadratic, and interactive factors (independent variables) are significant on citric acid yield. In other words, statistical validation reveals which of the operating parameters will actually greatly influence the production of citric acid from pineapple waste. The model generated for the effective prediction of citric acid production from pineapple waste using Aspergillus niger is given as follows:

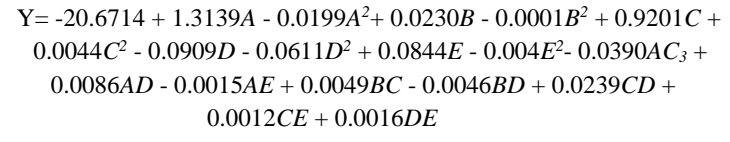

Where citric acid yield (Y) is the dependent variable; $A$ (temperature), $B$ (fermentation time), $C(\mathrm{pH}), D$ (methanol concentration) and $E$ (glucose concentration) are the independent parameters investigated on citric acid yield.

Furthermore, from the ANOVA (Table 2), the sum of squares (SS) values indicate minimal variability in the data set. $\mathrm{SS}$ is the square of the difference between the individual measurements and the mean of all measurements. It measures the amount of data variability and how far the individual measurements are from the mean. A high SS would indicate a lot of variability in the data.

\subsection{Effect of Operating Variables on Citric Acid Production}

Maximum production of citric acid through the process of fermentation by Aspergillus niger is rested on the availability of sufficient carbon sources [28, 29]. Many other factors such as temperature, $\mathrm{pH}$, and methanol concentration have been reported to also have different effects on the yield of citric acid [13]. The type and concentration of sugar have effects on citric acid production [23]. There should be minimum and maximum levels of sugar dosages in order to maximize citric acid production. High-level sugar in medium introduces intracellular compounds, may cause mycelium overgrowth which increases viscosity in the medium causing reduction in citric acid production [30]. For media having less than $2.5 \%$, minimal level of citric acid production is achieved [23]. In understanding the interactive effects of experimental factors on citric acid yield in this study, response surface and contour plots (Figs. 1 to 4) were utilized. Understanding the interactions of the operating parameters and conditions with citric acid production through the help of the surface and contour plots guide the decisions to be made in predicting the ranges of citric acid optimization.

\subsection{Effect of Methanol Concentration and Temperature on Citric Acid Yield}

Fig. (1) illustrates the interaction between temperature and methanol concentration and citric acid yield. The response surface plot shows that maximum citric acid production should be achieved at low methanol concentrations (not greater than 3 $\mathrm{g} / \mathrm{L}$ ) and temperature ranges between $20-30{ }^{\circ} \mathrm{C}$ (Fig. 1). The results obtained in this study are consistent with the literature, mesophilic temperatures $\left(25-35^{\circ} \mathrm{C}\right)$ have been reported as favorable for optimum yield of citric acid [31].

\subsection{Effect of Fermentation Time and pH on Citric Acid Production}

A high $\mathrm{pH}$ often results in the deactivation of the enzyme necessary for citric acid production. During fermentation, the $\mathrm{pH}$ of the medium is important because a low $\mathrm{pH}$ reduces the risk of contamination of the fermentation process [13]. A low $\mathrm{pH}$ of the fermentation medium inhibits and removes unwanted organic acids (oxalic acid and gluconic acid) thereby increasing the production of citric acid [23]. In addition, glucose oxidase may be activated reducing citric acid production [32]. Increasing $\mathrm{pH}$ beyond 4.5 during the production process reduces the final yield of citric acid [23]. It should be noted that the type of carbon substrate for the fermentation process also contribute to either increasing or decreasing the $\mathrm{pH}$ of the medium [2]. Fig. (2) shows that increasing the time for fermentation increases the $\mathrm{pH}$ of the medium. Though it appears from the response plot that more of the citric acid was produced, the optimum production points cannot be achieved in relation to other parameters as temperature, methanol concentration, and glucose loading. Looking closely in Fig. (2), the optimum conditions should be located between $\mathrm{pH} 3-5$ and fermentation time ranges of 4-8 $\mathrm{h}$.

\subsection{Effect of Temperature and $\mathrm{pH}$ on Citric Acid Production}

Temperature and $\mathrm{pH}$ of fermentation medium are essential parts for maximizing the production of citric acid by Aspergillus niger. Fig. (3) shows that maximum production of citric acid can be achieved for $\mathrm{pH}$ range 2.0-6.0 and a temperature range of $24-38{ }^{\circ} \mathrm{C}$. Maximum production of 15.51 $\mathrm{g} / \mathrm{L}$ citric acid was achieved at a $\mathrm{pH}$ of 3 and $30{ }^{\circ} \mathrm{C}$ fermentation temperature (Table 1). This guided our judgement for the optimization process. Increased citric acid production may be attributed to high enzymatic activity at increasing temperatures. This agrees with other relevant studies as reported in the literature [33]. 
Table 2. ANOVA for surface response quadratic polynomial model for citric acid production.

\begin{tabular}{|c|c|c|c|c|c|c|}
\hline Factor & Sum of squares (SS) & Degree of Freedom & Mean square & F-value & P-value & Interpretation \\
\hline A & 5.50 & 1 & 5.50 & 5.68 & 0.0545 & Significant \\
\hline $\mathrm{A}^{2}$ & 4.02 & 1 & 4.02 & 4.15 & 0.0877 & Marginally significant \\
\hline $\mathrm{B}$ & 11.13 & 1 & 11.14 & 11.49 & 0.0147 & Significant \\
\hline $\mathrm{B}^{2}$ & 1.14 & 1 & 1.17 & 1.18 & 0.3196 & - \\
\hline $\mathrm{C}$ & 6.47 & 1 & 6.47 & 6.68 & 0.0414 & Significant \\
\hline $\mathrm{C}^{2}$ & 2.26 & 1 & 2.26 & 2.33 & 0.1772 & - \\
\hline $\mathrm{D}$ & 8.27 & 1 & 8.27 & 8.53 & 0.0266 & Significant \\
\hline $\mathrm{D}^{2}$ & 0.39 & 1 & 0.39 & 0.40 & 0.5488 & - \\
\hline $\mathrm{E}$ & 0.07 & 1 & 0.07 & 0.07 & 0.8013 & - \\
\hline$E^{2}$ & 4.17 & 1 & 4.17 & 4.30 & 0.0833 & Marginally significant \\
\hline $\mathrm{AB}$ & 0.49 & 1 & 0.49 & 0.51 & 0.5031 & - \\
\hline $\mathrm{AC}$ & 4.36 & 1 & 4.37 & 4.51 & 0.0779 & Marginally significant \\
\hline $\mathrm{AD}$ & 0.39 & 1 & 0.39 & 0.41 & 0.5444 & - \\
\hline $\mathrm{AE}$ & 2.13 & 1 & 2.14 & 2.21 & 0.1878 & - \\
\hline $\mathrm{BC}$ & 2.03 & 1 & 2.03 & 2.09 & 0.1974 & - \\
\hline $\mathrm{BD}$ & 3.69 & 1 & 3.69 & 3.82 & 0.0986 & Marginally significant \\
\hline $\mathrm{BE}$ & 2.08 & 1 & 2.08 & 2.15 & 0.1929 & - \\
\hline $\mathrm{CD}$ & 0.65 & 1 & 0.65 & 0.68 & 0.4410 & - \\
\hline $\mathrm{CE}$ & 0.59 & 1 & 0.59 & 0.61 & 0.4629 & - \\
\hline $\mathrm{DE}$ & 0.17 & 1 & 0.17 & 0.17 & 0.6864 & - \\
\hline Error & 5.8139 & 6 & 0.9690 & - & - & - \\
\hline Total SS & 53.0265 & 26 & - & - & - & - \\
\hline
\end{tabular}
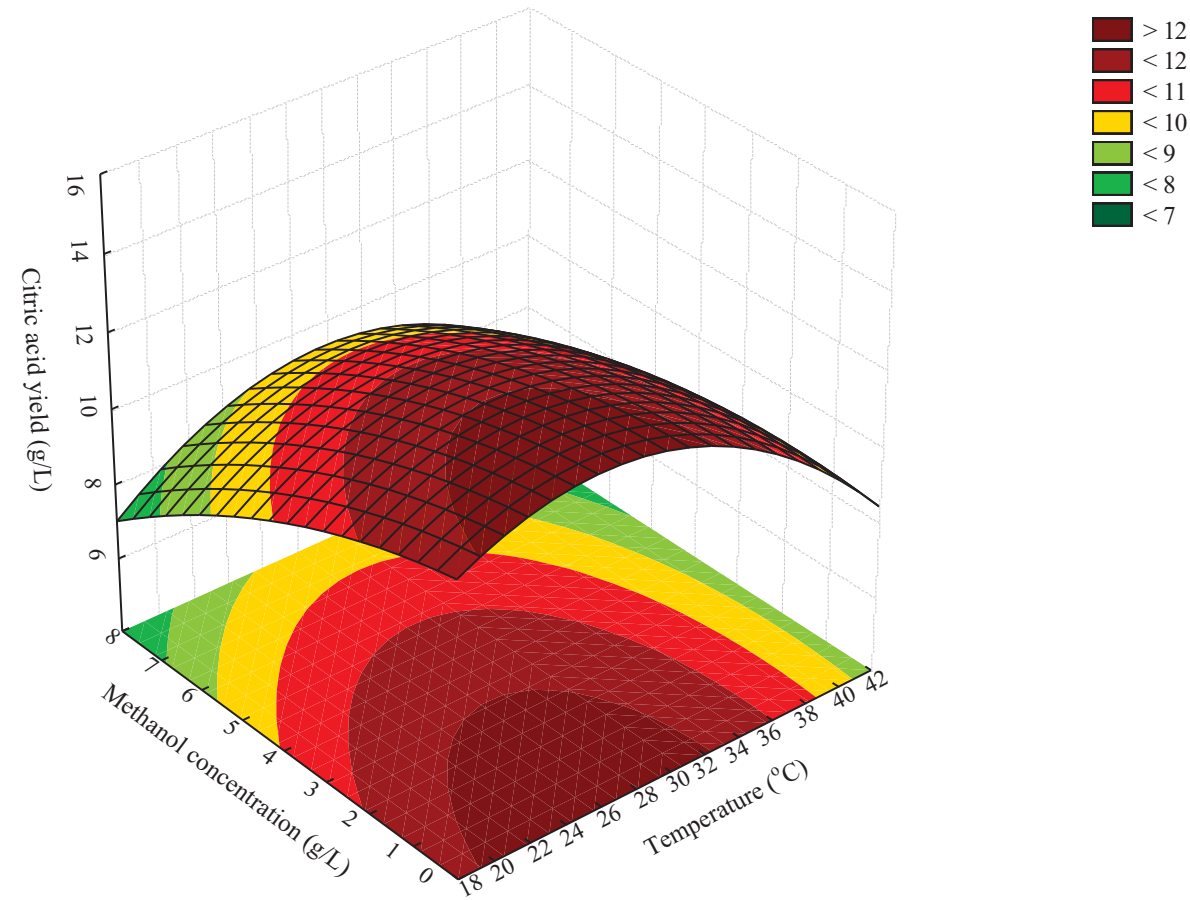

. (1). Response surface and contour plot showing the effect of Methanol concentration and Temperature on citric acid yield. 


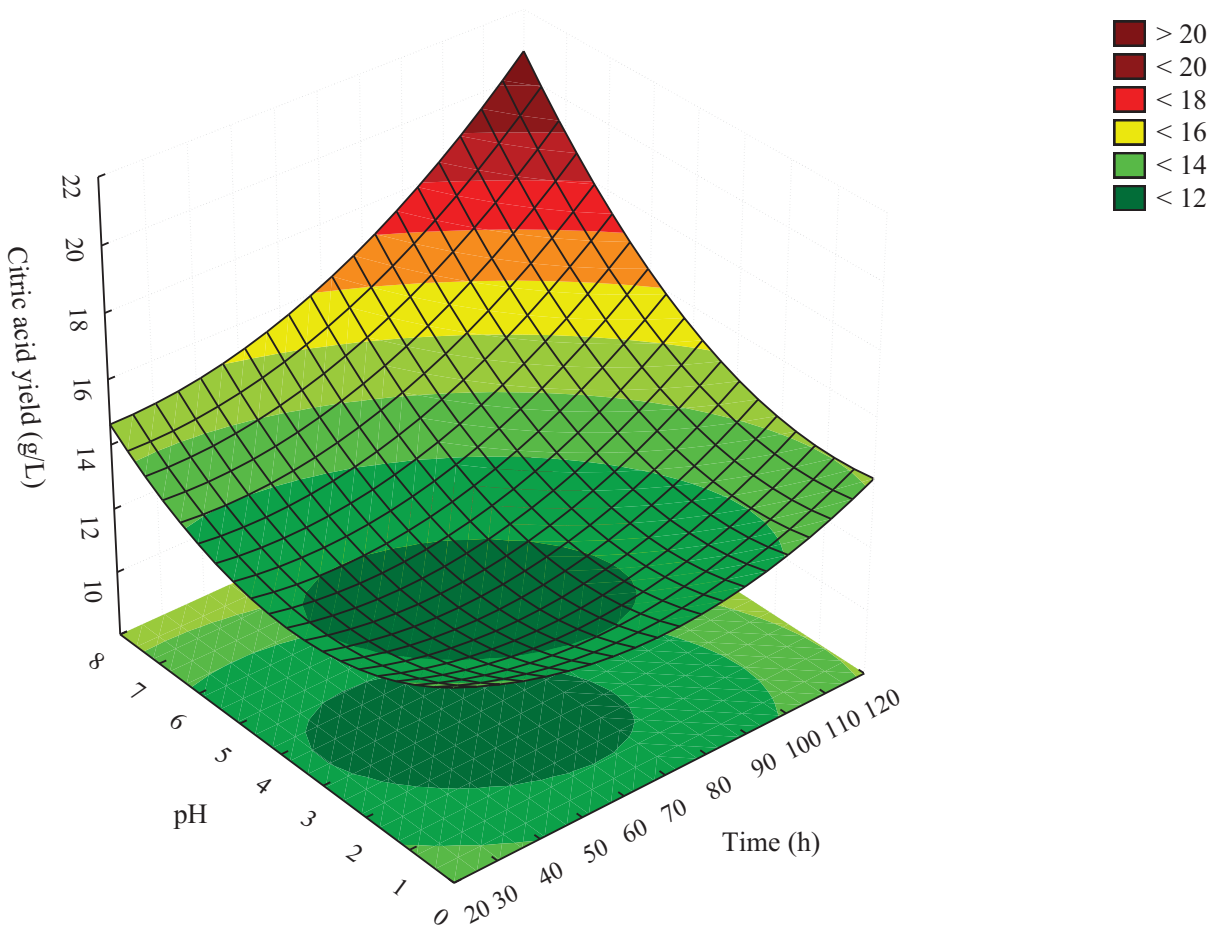

Fig. (2). Response surface and contour plot showing the effect of $\mathrm{pH}$ and fermentation Time on citric acid yield.

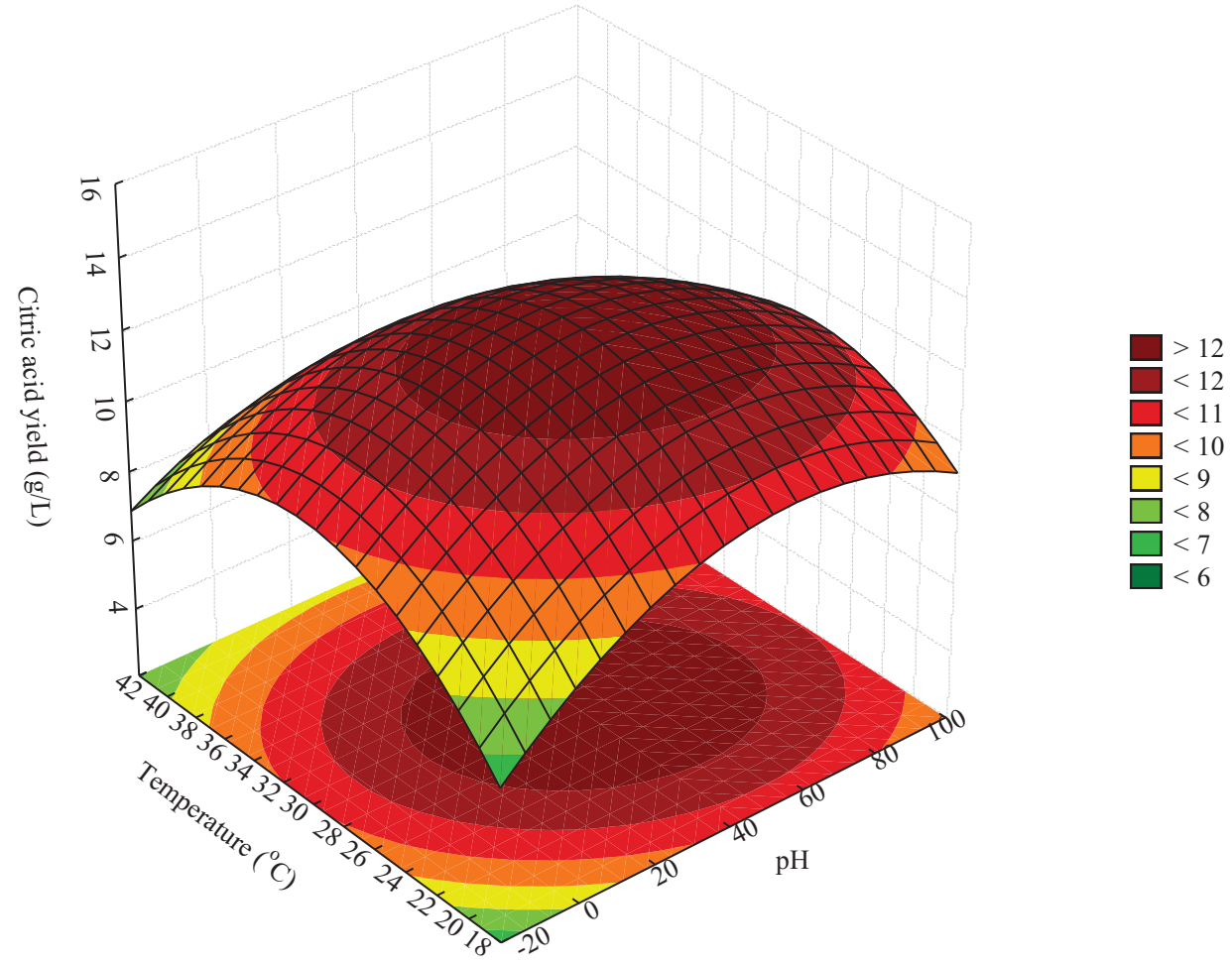

Fig. (3). Response surface and contour plot showing the effect of Temperature and $\mathrm{pH}$ on citric acid yield. 


\subsection{Effect of Temperature and Fermentation Time on Citric Acid Production}

The interactive effect of fermentation time and temperature on citric acid yield is as shown in Fig. (4). A shorter production time is of great importance. This reduces the cost of production.

\subsection{Optimization and Validation of the Operating Conditions}

Eq. (7) was solved by the method of Myers and Montgomery [34] to obtain the optimum parameters required for the generation of citric acid. The surface responses, as well as the ANOVA results, were used to predict the optimum conditions of citric acid generated. Responses predicted for citric acid production were evaluated using Eq. (7). These results showed that methanol concentration above $2 \%(\mathrm{v} / \mathrm{v})$ is suitable for citric acid production. The ANOVA analysis of the methanol concentration factor provided a low probability value of 0.0266 on the linear term (Table 2). Table 2 shows the analysis of the developed model using ANOVA.

Furthermore, Table 2 shows that the linear effects of the temperature, time, $\mathrm{pH}$, and methanol concentration to be significant on citric acid production. The quadratic terms of temperature, glucose concentration, the interactive effect of temperature-time, and the interactive effect of time and methanol concentration are marginally significant on citric acid production. These evaluations follow the trends as shown through the response surface plots (Figs. 1 to 4). From the regression model (Eq. 7), the coefficient of determination $\left(R^{2}\right)$ of 0.895 was obtained by comparing the experimental with the predicted values.

This indicates that $89.5 \%$ of the observed data can be demonstrated by the model while only $10.5 \%$ cannot be accounted for by the model. ANOVA shows a developed model to be marginally significant with a probability value of 0.060 . The observed (experimental) and predicted values were compared and noted to be in close agreements (Fig. 5), further validating the model. The differences between the experimental and predicted values, that is, the residuals (Table 1), were also within the allowable ranges. Predicted optimum conditions for citric acid production were $41 \mathrm{~g} / \mathrm{L}$ glucose concentration, $5.5 \%(\mathrm{v} / \mathrm{v})$ methanol, $45 \mathrm{~h}$ fermentation time, $\mathrm{pH}$ of 5.4 , and temperature of $34{ }^{\circ} \mathrm{C}$ given a yield of $13.5 \mathrm{~g} / \mathrm{L}$ citric acid.

Optimal conditions were validated by carrying out another duplicated set of an experiment which gave the optimum conditions as $38 \mathrm{~g} / \mathrm{L}$ of glucose concentration, $3 \%(\mathrm{v} / \mathrm{v})$ of methanol, $50 \mathrm{~h}$ of fermentation time, $\mathrm{pH}$ of 4.3 and temperature of $30{ }^{\circ} \mathrm{C}$ which yielded $15.51 \mathrm{~g} / \mathrm{L}$ citric acid.

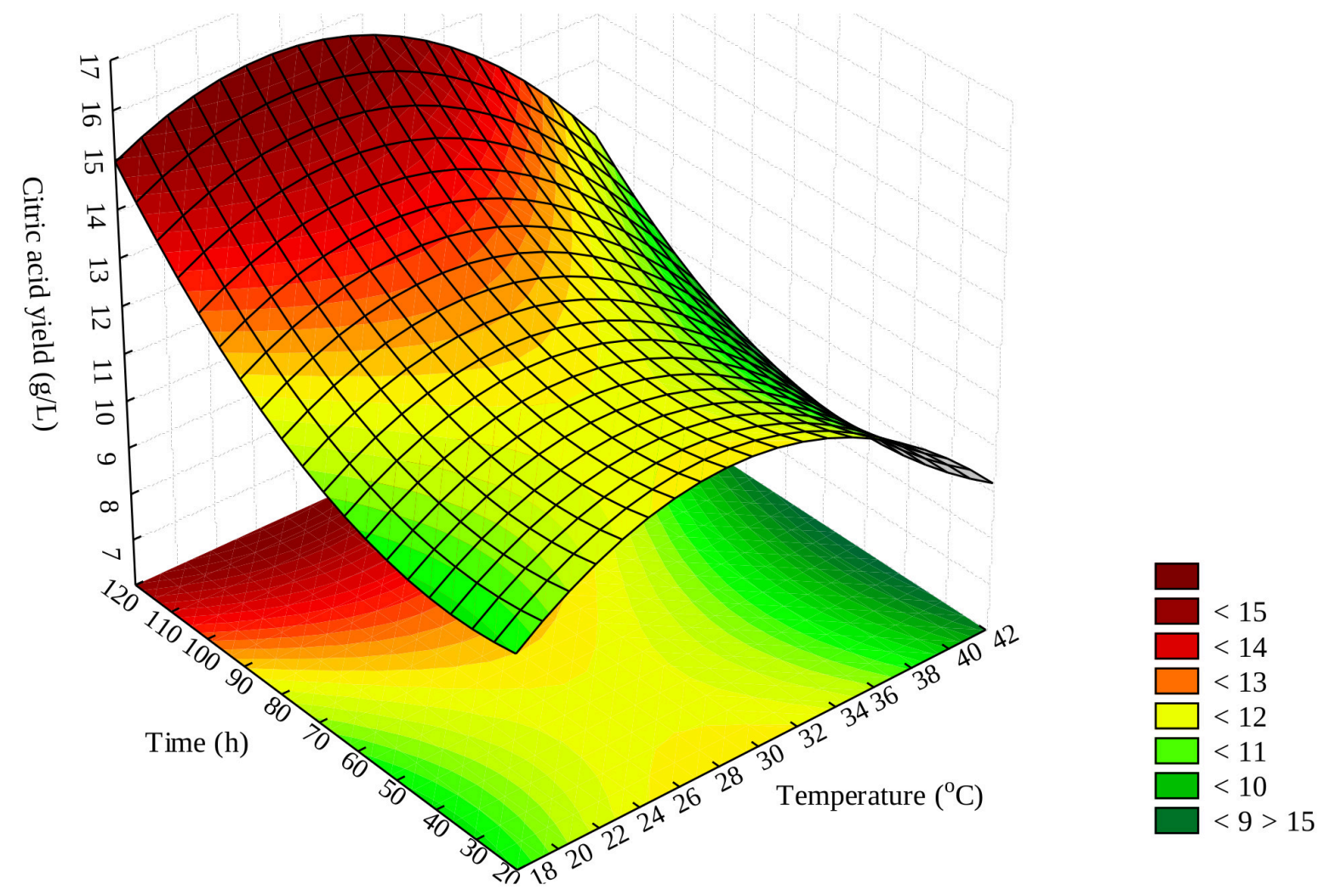

Fig. (4). Response surface and contour plot showing the effect of Temperature and Time on citric acid yield. 


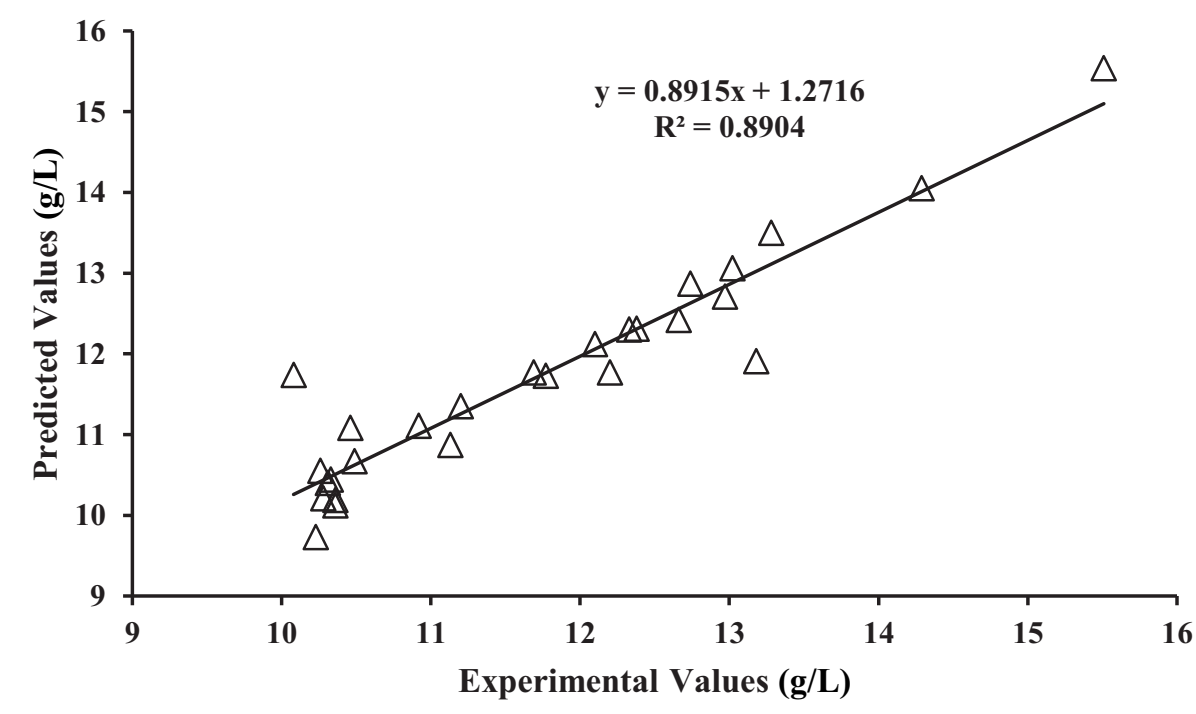

Fig. (5). Predicted values versus Experimental values of citric acid production.

\section{CONCLUSION}

The optimal operating conditions were determined at 38 $\mathrm{g} / \mathrm{L}$ of glucose concentration, $3 \%(\mathrm{v} / \mathrm{v})$ of methanol, fermentation time of $50 \mathrm{~h}, \mathrm{pH} 4.3$ and temperature of $30^{\circ} \mathrm{C}$. It can be noted that pineapple waste (a low-cost substrate) is a possible substrate that can be used for citric acid production. However, low yields of citric acid were produced under the prevailing conditions in this study. Future studies will focus on improving the operating conditions such as using different carbon sources like sucrose or fructose instead of glucose in order to maximize citric acid production. The production process highlighted in this work is a possible solution to alleviate the negative impacts on the environment caused by the disposal of pineapple waste.

\section{CONSENT FOR PUBLICATION}

Not applicable.

\section{AVAILABILITY OF DATA AND MATERIALS}

Not applicable.

\section{FUNDING}

None

\section{CONFLICT OF INTEREST}

The authors declare no conflict of interest, financial or otherwise.

\section{ACKNOWLEDGEMENTS}

The authors are grateful to the management of Covenant University, Ota, Nigeria for sponsoring the publication of this article.

\section{REFERENCES}

[1] M. Berovic, and M. Legisa, "Citric acid production", Biotechnol.
Annu. Rev., vol. 13, pp. 303-343, 2007.

[http://dx.doi.org/10.1016/S1387-2656(07)13011-8] [PMID: 1787 5481]

[2] P.T. Sekoai, A.O. Ayeni, and M.O. Daramola, "Parametric optimization of citric acid production from apple pomace and corn steep liquor by a wild type strain of Aspergillus niger: A Response surface methodology approach", Internatl. J. Eng. Res. Afr., vol. 36, pp. 98-113, 2018.

[http://dx.doi.org/10.4028/www.scientific.net/JERA.36.98]

[3] W.A. Lotfy, K.M. Ghanem, and E.R. El-Helow, "Citric acid production by a novel Aspergillus niger isolate: II. Optimization of process parameters through statistical experimental designs", Bioresour. Technol., vol. 98, no. 18, pp. 3470-3477, 2007. [http://dx.doi.org/10.1016/j.biortech.2006.11.032] [PMID: 17317159]

[4] A.J. Murad, and K.S. Al-Delaimy, "Citric acid production from whey with Sugars and additives by Aspergillus niger", Afr. J. Biotechnol., vol. 2, pp. 356-359, 2003.

[http://dx.doi.org/10.5897/AJB2003.000-1073]

[5] S.E.A. Bakhiet, and E.A. Al-Mokhtar, "Production of citric acid by Aspergillus niger using sugarcane molasses as substrate", Jordan J. Biol. Sci., vol. 8, pp. 211-215, 2015.

[http://dx.doi.org/10.12816/0026960]

[6] FAO, The state of food and agriculture 2010-2011: Women in agriculture. [http://www.fao.org/docrep/013/i2050e/i2050e.pdf. Retrieved on 12 October, 2018]

[7] "Commercial Agriculture Development Project, Manual (2012)", Available at http://documents.worldbank.org/curated/en/4056515217 57130496/pdf/Nigeria-NG-Commercial-Agriculture-Development.pdf

[8] N.S. Esiobu, and G.C. Onubuogu, "Determinant of Income from pineapple Production in Imo State, Nigeria. An econometric model approach", J. Econ. Sustain. Dev., vol. 5, pp. 122-132, 2014. [https://www.iiste.org/Journals/index.php/JEDS/article/view/16739/17 $100]$.

[9] O.A. Makinde, S.M. Odeyinka, and S.K. Ayandiran, "Simple and quick method for recycling pineapple waste into animal feed", Livest. Res. Rural Dev., vol. 23, p. 9, 2011. [https://www.lrrd.cipav.org.co/ 1rrd23/9/maki23188.htm. Retrieved on 12 October, 2018].

[10] U. Atul, P.L. Jeewan, and T. Shinkichi, "Utilization of Pineapple Waste: A Review", J. Food Sci. Technol Nepal, vol. 6, pp. 10-18, 2010.

[11] A.O. Ayeni, and M.O. Daramola, "Lignocellulosic biomass beneficiation: Evaluation of oxidative and non-oxidative pretreatment methodologies for South African corn cob", J. Environ. Chem. Eng., vol. 5, pp. 1771-1779, 2017.

[http://dx.doi.org/10.1016/j.jece.2017.03.019]

[12] A.A. Awosusi, A. Ayeni, R. Adeleke, and M.O. Daramola, "Effect of water of crystallization on the dissolution efficiency of molten zinc 
chloride hydrate salts during the pretreatment of corncob biomass", $J$. Chem. Technol. Biotechnol., vol. 92, pp. 2468-2476, 2017.

[http://dx.doi.org/10.1002/jctb.5266]

[13] A.O. Adeoye, A. Lateef, and E.G. Gueguim Kana, "Optimization of citric acid production using a mutant strain of Aspergillus niger on cassava peel substrate", Biocatal. Agric. Biotechnol., vol. 4, pp. 568-574, 2015.

[http://dx.doi.org/10.1016/j.bcab.2015.08.004]

[14] T.C. Cairns, C. Nai, and V. Meyer, "How a fungus shapes biotechnology: 100 years of Aspergillus niger research", Fungal Biol. Biotechnol., vol. 5, p. 13, 2018.

[http://dx.doi.org/10.1186/s40694-018-0054-5] [PMID: 29850025]

[15] E. Papadaki, and F.T. Mantzouridou, "Citric acid production from the integration of Spanish-style green olive processing wastewaters with white grape pomace by Aspergillus niger", Bioresour. Technol., vol. 280, pp. 59-69, 2019.

[http://dx.doi.org/10.1016/j.biortech.2019.01.139] [PMID: 30754006]

[16] D.A. Rzechonek, A. Dobrowolski, W. Rymowicz, and A.M. Mirończuk, "Aseptic production of citric and isocitric acid from crude glycerol by genetically modified Yarrowia lipolytica", Bioresour. Technol., vol. 271, pp. 340-344, 2019.

[http://dx.doi.org/10.1016/j.biortech.2018.09.118] [PMID: 30292133]

[17] S.R. Ali, Z. Anwar, M. Irshad, S. Mukhtar, and N.T. Warraich, "Biosynthesis of citric acid from single and co-culture-based fermentation technology using agro-wastes", J. Rad. Res. Appl. Sci., vol. 9, pp. 57-62, 2016.

[http://dx.doi.org/10.1016/j.jrras.2015.09.003]

[18] A.R. Angumeenal, and D. Venkappayya, "An overview of citric acid production", Lebensm. Wiss. Technol., vol. 50, pp. 367-370, 2013. [http://dx.doi.org/10.1016/j.lwt.2012.05.016]

[19] R. Ciriminna, F. Meneguzzo, R. Delisi, and M. Pagliaro, "Citric acid: emerging applications of key biotechnology industrial product", Chem. Cent. J., vol. 11, p. 22, 2017.

[http://dx.doi.org/10.1186/s13065-017-0251-y] [PMID: 28326128]

[20] H. Yaakob, R.N. Ahmed, S.K. Daud, R.A. Malek, and R.A. Rahman, "Optimization of ingredient and processing levels for the production of coconut yogurt using response surface methodology", Food Sci. Biotechnol., vol. 21, pp. 933-940, 2012.

[http://dx.doi.org/10.1007/s10068-012-0123-0]

[21] A.O. Ayeni, and H.K. Hymore, "S.N. Mudliar S.C. Deshmukh, D.B. Satpute, J.A. Omoleye, and R.A. Pandey, "Hydrogen peroxide and lime based oxidative pretreatment of wood waste to enhance enzymatic hydrolysis for a biorefinery: Process parameters optimization using response surface methodology", Fuel, vol. 106, pp. 187-194, 2013.

[http://dx.doi.org/10.1016/j.fuel.2012.12.078]

[22] A.F. Saleh, E. Kamarudin, A.B. Yaacob, A.W. Yusso, and M.A. Abdullah, "Optimization of biomethane production by anaerobic digestion of palm oil mill effluent using response surface methodology", Asia-Pac. J. Chem. Eng., vol. 7, pp. 353-360, 2012. [http://dx.doi.org/10.1002/apj.550]
[23] M. Papagianni, "Advances in citric acid fermentation by Aspergillus niger: Biochemical aspects, membrane transport and modeling", Biotechnol. Adv., vol. 25, no. 3, pp. 244-263, 2007. [http://dx.doi.org/10.1016/j.biotechadv.2007.01.002] [PMID: 1733 7335]

[24] A.O. Ayeni, J.A. Omoleye, F.K. Hymore, and R.A. Pandey, "Effective alkaline peroxide oxidation pretreatment of shea-tree sawdust for the production of biofuels: Kinetics of delignification and enzymatic conversion to sugar and subsequent production of ethanol by fermentation using Saccharomyces cerevisiae", Braz. J. Chem. Eng., vol. 33, pp. 33-45, 2016.

[http://dx.doi.org/10.1590/0104-6632.20160331s20140258]

[25] AOAC Official Methods of Analysis., 16th ed Association of Official Analytical Chemist: Washington, D.C., 1995.

[26] S.O. Kareem, I. Akpan, and O.O. Alebiowu, "Production of citric acid by Aspergillus niger using pineapple waste", Malays. J. Microbiol., vol. 6, pp. 161-165, 2010. [https://pdfs.semanticscholar.org/f985/ a7a479469ebe6c3339bcab3d8c96e41d4e2f.pdf].

[27] M.N. Bari, M.Z. Alam, S.A. Muyibi, P. Jamal, and Abdullah-AlMamun, "Improvement of production of citric acid from oil palm empty fruit bunches: optimization of media by statistical experimental designs", Bioresour. Technol., vol. 100, no. 12, pp. 3113-3120, 2009. [http://dx.doi.org/10.1016/j.biortech.2009.01.005] [PMID: 19231166]

[28] W. Jianlong, "Enhancement of citric acid production by Aspergillus niger using n-dodecane as an oxygen-vector", Process Biochem., vol. 35, pp. 1079-1083, 2000 .

[http://dx.doi.org/10.1016/S0032-9592(00)00142-4]

[29] T. Roukas, "Citric and gluconic acid production from fig by Aspergillus niger using solid-state fermentation", J. Ind. Microbiol. Biotechnol., vol. 25, no. 6, pp. 298-304, 2000. [http://dx.doi.org/10.1038/sj.jim.7000101] [PMID: 11320416]

[30] M.P.D. Prasad, V. Sridevi, N.V. Surendrababu, O.V.S. Reddy, and N Harsha, "“Studies on fermentative production of citric acid by Aspergillus niger isolate using sorghum malt and its optimization" Internatl. J Inno", Res. Sci. Eng. Technol., vol. 2, pp. 2961-2968, 2013.

[31] O.B. Fawole, and S.A. Odunfa, "Some Factors Affecting Production of Pectin Enzymes by Aspergillus niger", Internatl. Biodeteriorat. Biodegrad., vol. 52, pp. 223-227, 2003.

[http://dx.doi.org/10.1016/S0964-8305(03)00094-5]

[32] C.P. Kubicek, M. Röhr, and H.J. Rehm, "Aconitase and citric acid fermentation by Aspergillus niger", Appl. Environ. Microbiol., vol. 50, no. 5, pp. 1336-1338, 1985 . [PMID: 4091562]

[33] S.O. Kareem, and R.A. Rahman, "Utilization of banana peels for citric acid production by Aspergillus niger", Agric. Biol. J. N. Am., vol. 4, pp. 384-387, 2013.

[http://dx.doi.org/10.5251/abjna.2013.4.4.384.387]

[34] R.H. Myers, D.C. Montgomery, and C.M. Anderson-Cook, Response surface methodology: process and product optimization using designed experiments., 4th ed John Wiley \& Sons: New York, USA, 2016.

(C) 2019 Ayeni et al.

This is an open access article distributed under the terms of the Creative Commons Attribution 4.0 International Public License (CC-BY 4.0), a copy of which is available at: https://creativecommons.org/licenses/by/4.0/legalcode. This license permits unrestricted use, distribution, and reproduction in any medium, provided the original author and source are credited. 